\title{
Effects of smoke exposure and other lifestyle factors on pain response to electrical stimulation in women
}

\author{
Joy Yenn May Wee BSc MSc MD FRCPC ${ }^{1}$, Wilma M Hopman MA²
}

JYM Wee, WM Hopman. Effects of smoke exposure and other lifestyle factors on pain response to electrical stimulation in women. Pain Res Manage 2008;13(3):231-235.

BACKGROUND: A relationship between smoking and development of pain syndromes has been suggested in the literature. The present study examined associations between smoke exposure and other related variables, and pain response to suprathreshold electrical stimulation.

METHODS: Subjects were prospectively recruited from a population referred to an electrodiagnostic clinic. Information about age, smoke exposure, caffeine and alcohol consumption was obtained, as well as documented objective signs of stress through physical assessment. One investigator applied two standardized $0.1 \mathrm{~ms}$ electrical stimulations ( $50 \mathrm{~mA}$ followed by $100 \mathrm{~mA}$ ) to asymptomatic extremities at the beginning of each electrodiagnostic session, using consistent technique. Subjects used a visual analogue scale to indicate the level of pain felt after each stimulation.

RESULTS: Two hundred fifteen women were included. Current smokers and those currently exposed to second-hand smoke had significantly higher pain ratings $(\mathrm{P}=0.003$ for $50 \mathrm{~mA}, \mathrm{P}=0.005$ for $100 \mathrm{~mA}$ ) than those not currently exposed to smoke. Time since exposure was negatively associated with pain ratings. Those with objective signs of stress reported higher levels of pain, which was significant for the $100 \mathrm{~mA}$ stimulation $(\mathrm{P}=0.046)$. Linear regression modelling indicated that current smoke exposure and alcohol use were associated with higher pain ratings at both $50 \mathrm{~mA}$ and $100 \mathrm{~mA}$, while stress was associated with higher pain ratings and older age was associated with lower pain ratings at $100 \mathrm{~mA}$ only.

INTERPRETATION: Exposure to cigarette smoke is significantly related to higher reported levels of pain experienced in response to electrical stimulation in this study population. Exposure to smoke can add 10 points to the 100 -point visual analogue scale compared with subjects without exposure, with alcohol use adding another eight points. Reported pain decreases as length of time since previous exposure to smoke increases.

Key Words: Electrical stimulation; Pain response; Smoke exposure; Women

\author{
Les effets de l'exposition à la fumée de cigarette \\ et à d'autres facteurs reliés au mode de vie sur la \\ réaction à la stimulation électrique chez les \\ femmes
}

HISTORIQUE : Les publications laissent supposer qu'il existe un lien entre le tabagisme et l'apparition de syndromes de douleur. La présente étude a permis d'évaluer les associations entre l'exposition à la fumée de cigarette ainsi qu'à des variables connexes et les réactions de douleur à une stimulation électrique supérieure au seuil.

MÉTHODOLOGIE : Les sujets ont été recrutés prospectivement au sein d'une population orientée vers une clinique électrodiagnostique. Les auteurs ont colligé l'information au sujet de leur âge, de l'exposition à la fumée et à la caféine et de leur consommation d'alcool et ont documenté les signes objectifs de stress par une évaluation physique. Un chercheur a appliqué deux stimulations électriques standardisées de $0,1 \mathrm{~ms}(50 \mathrm{~mA}$ suivis de $100 \mathrm{~mA})$ à des extrémités asymptomatiques au début de chaque séance électrodiagnostique, au moyen d'une technique uniforme. Les sujets ont utilisé une échelle analogique visuelle pour indiquer le taux de douleur ressentie après chaque stimulation.

RÉSULTATS : Deux cent quinze femmes ont été incluses dans l'étude. Les fumeuses et celles qui étaient exposées à la fumée secondaire avaient des évaluations de la douleur considérablement plus élevées ( $\mathrm{P}=0,003$ pour $50 \mathrm{~mA}$, $\mathrm{P}=0,005$ pour $100 \mathrm{~mA}$ ) que ceux qui n'étaient pas exposés à la fumée. La période depuis l'exposition était inversement proportionnelle à l'évaluation de la douleur. Les sujets qui présentaient des signes objectifs de stress déclaraient des taux plus élevés de douleur, significatifs à l'égard de la stimulation de $100 \mathrm{~mA}(\mathrm{P}=0,046)$. Selon le modèle de régression linéaire, l'exposition à la fumée et la consommation d'alcool s'associaient à des évaluations plus élevées de la douleur à la fois à $50 \mathrm{~mA}$ et à $100 \mathrm{~mA}$, tandis que le stress était relié à des évaluations plus élevées de la douleur et que le plus grand âge s'associait à des évaluations moins élevées de la douleur à $100 \mathrm{~mA}$ seulement. INTERPRÉTATION : L'exposition à la fumée de cigarette est reliée de façon appréciable à des taux plus élevés de douleur ressentie à une stimulation électrique au sein de la population à l'étude. L'exposition à la fumée peut ajouter dix points à l'échelle analogique visuelle de 100 points par rapport aux sujets qui n'y sont pas exposés, la consommation d'alcool ajoutant huit points supplémentaires. La douleur déclarée diminue à mesure qu'augmente la période depuis la dernière exposition à la fumée.
$\mathrm{T}$ There is evidence to support an association between cigarette smoking and pain conditions. Two systematic literature reviews of back pain and smoking $(1,2)$ suggest at least a weak association between smoking and pain in a majority of epidemiological studies, but cite only a handful of prospective studies. Several studies of conditions such as back pain (3), carpal tunnel syndrome (4) and complex regional pain syndrome (5) have supported an association of pain with higher smoking prevalence. Similarly, increased health problems among teenage smokers have been noted, including increased headache, neck and shoulder pain (6).

On the other hand, older small studies performed on smokers give conflicting results, indicating that nicotine administration may reduce pain perception in smokers $(7,8)$. However, another study (9) reported no effect of smoking on pain thresholds. One study found no relationship between nicotine and painful diabetic neuropathy (10), while another small study noted differences in the effect of nicotine in men and

${ }^{1}$ Department of Physical Medicine $\mathcal{E}$ Rehabilitation, Queen's University, and Providence Care, St Mary's of the Lake Hospital Site; ${ }^{2}$ Department of Community Health and Epidemiology, Queen's University, and the Clinical Research Centre, Kingston General Hospital, Kingston, Ontario Correspondence and reprints: Dr Joy Wee, Providence Care, St Mary's of the Lake Hospital Site, Postal Bag 3600, Kingston, Ontario K7L 5A2.

Telephone 613-544-2143, fax 613-544-4614, e-mail weej@queensu.ca 
women on electrocutaneous stimulation, suggesting no effect of nicotine in women (11).

The present paper examines the effect of natural, nonexperimental cigarette smoke exposure on pain reporting to experimental electrical stimulation in women, because there is evidence that women may experience experimental pain differently from men (12). We sought to determine whether pain perception is heightened in current smokers and those exposed to second-hand smoke, compared with ex-smokers and nonsmokers. One cannot perform a natural exposure survey without understanding exposure to other related factors thought to have an impact on pain perception. These include stress, caffeine intake, alcohol consumption and age. Stress is a factor recognized to exacerbate pain $(13,14)$. Animal studies show that some histaminergic neuronal groups are activated with specific types of stress (15). Stress can have manifold effects on physical health (16), and may influence use of substances, such as alcohol $(17,18)$ and nicotine $(16)$. Certain objective clinical signs, namely dermatographia and hyperhidrosis, are also associated with higher self-reported pain perception (19). With respect to caffeine, one group reported that caffeine consumption reduced leg muscle pain (20). Regarding the relationship between alcohol and pain, one study (18) suggested that in rats, a genetic predisposition toward high levels of alcohol consumption may be associated with decreased pain thresholds. Some sources suggest a negative relationship between age and pain perception (21-23).

\section{METHODS}

Ethics approval was obtained through the Queen's University and Providence Care (previously Providence Continuing Care Centre) hospital research ethics committees. Three hundred thirty-two consecutive patients referred for testing in an electromyography clinic from January 2005 to February 2007 were enrolled, after they indicated interest in participating in the study through the clinic nurse; written consent was obtained from all subjects. They were generally referred for varying complaints of localized paresthesia or discomfort in one or more extremities, of variable duration, from one week to several years. Excluded were subjects with peripheral neuropathy, widespread pain syndromes and use of recreational drugs. Seven women who were excluded were between the ages of 41 and 83 years (mean $[ \pm S D] 56.6 \pm 13.5$ ). Five had peripheral neuropathy and widespread or severe chronic pain syndromes. One subject was excluded because of recreational drug use, and one subject had Alzheimer's disease. If cognition was questioned, a simple screen of attention, the spelling of 'WORLD' in reverse, was administered. Testing continued if no errors were found, because all that was required of subjects was the ability to understand instructions and attend to one's pain level for a few seconds to record it on the scale described below. This test of attention is included in the Folstein MiniMental Status Examination (24).

The study included 117 men and 215 women, but because of the significant differences found in sex $(P=0.002)$, and the unequal sex distribution in the sample, the results for the predominant sex, namely, women, are presented. Because of the relationships mentioned in the introduction, subjects were asked about current and past smoke exposure, regular caffeine intake and alcohol consumption. Subjects also reported on the presence or absence of ongoing stress in their lives, under the following categories: 'financial', 'work', 'health', 'family' or 'other'. Subject age was recorded. The study was designed for adequate power to include all these factors, estimating the required numbers of subjects from results obtained in a smaller related study completed at the authors' centre in 1996 by a different investigator (unpublished). A standardized data collection form was used to record data. During the examination, presence or absence of objective clinical findings of stress (namely hyperhidrosis and dermatographia) were documented by the first author, an experienced specialist physician in physical medicine and rehabilitation. These signs are wellrecognized by physicians who routinely assess people for pain conditions as physiological changes attributed to the stress response $(25,26)$.

Similar to other experimental protocols, consistent low intensities were used in applying painful stimuli (27). From past experience in this electrodiagnostic laboratory, the majority of referred individuals easily tolerated these levels of stimulation when applied through the Neuromax 1002 (XLTEK, Canada) electromyography machine. Each subject received two standardized $0.1 \mathrm{~ms}$ suprathreshold electrical stimulations, consisting of one stimulation each at $50 \mathrm{~mA}$, then at $100 \mathrm{~mA}$. Visual analogue scale (VAS) ratings, consisting of a horizontal line $100 \mathrm{~mm}$ long anchored by words at each end, were used because they have been validated for assessing subjective pain intensity $(28,29)$. The VAS ratings are referred to below as VAS1 $(50 \mathrm{~mA})$ and VAS2 $(100 \mathrm{~mA})$. The same investigator consecutively applied the stimulations to an asymptomatic extremity at the beginning of the electrodiagnostic session, using consistent technique, equipment and settings. Standard median motor nerve conduction study sites were used in the protocol (28), with surface active recording electrodes at the thenar eminence motor point and reference electrode at the lateral aspect of the second metacarpophalangeal joint. Subjects were asked to immediately mark the level of pain felt on a horizontally oriented VAS with anchors of 'No pain whatsoever' (score of 0 ) and 'Worst pain imaginable' (score of 100) after each stimulation was applied. These scores were individually recorded by the first author. To check agreement, a random sample of $10 \%$ of the marked scoring sheets was remeasured and verified by another individual with no patient contact, for accuracy.

Data were entered into an Excel spreadsheet (Microsoft, USA) and imported into SPSS (Version 14.0, SPSS Inc, USA) for analysis. Following an assessment of the distribution of the VAS scores, descriptive analyses (frequencies, means, SDs), independent samples $t$ tests and one-way ANOVA were used to examine the association between categorical variables and the two VAS ratings. For the ANOVA, Tukey's posthoc tests were used to identify significant between-group differences. Categorical data such as smoking and sex were compared using the Pearson $\chi^{2}$ test.

Multivariable linear regression was used to develop predictive models for VAS1 and VAS2. Variables were inserted into the regression on the basis of a $\mathrm{P}<0.20$ in the bivariate analysis, so as not to miss any trend. For the regressions, 'smoke exposure' was collapsed into two groups of 'current smoke exposure' (current smokers and current second-hand exposure) and 'no current smoke exposure' (never smoked, previous smokers, previous second-hand exposure) for statistical power and clarity. Likewise, 'alcohol use' was collapsed into yes (occasional, regular, abuse) and no (none, previous), as was caffeine (none versus occasional or more). The variable 'signs 
TABLE 1

Subject characteristics based on smoking exposure history

\begin{tabular}{|c|c|c|c|c|c|c|}
\hline Characteristic & Nonsmoker, $n=40$ & Current smoker, n=61 & Ex-smoker, $n=69$ & $\begin{array}{c}\text { Current } \\
\text { second hand, } n=8\end{array}$ & $\begin{array}{c}\text { Previous } \\
\text { second hand, } n=37\end{array}$ & $\mathbf{P}$ \\
\hline Age, years (mean $\pm S D$ ) & $48.5 \pm 16.3$ & $44.6 \pm 9.8$ & $51.8 \pm 15.8$ & $55.6 \pm 19.3$ & $53.0 \pm 14.7$ & 0.015 \\
\hline Use caffeine, $n(\%)$ & $27(67.5)$ & $54(88.5)$ & $60(87.0)$ & $5(62.5)$ & $29(78.4)$ & 0.031 \\
\hline Use alcohol, n (\%) & $23(57.5)$ & $39(63.9)$ & $45(66.2)$ & $3(37.5)$ & $18(48.6)$ & 0.26 \\
\hline Nerve compression, $\mathrm{n}(\%)$ & $26(65.0)$ & $44(72.1)$ & $50(72.5)$ & $6(75.0)$ & $25(67.6)$ & 0.91 \\
\hline Non-neural diganosis, n (\%) & $13(32.5)$ & $21(34.4)$ & $22(31.9)$ & $2(25.0)$ & $12(32.4)$ & 0.99 \\
\hline
\end{tabular}

TABLE 2

Associations between lifestyle factors and pain perception

\begin{tabular}{lccccccc}
\hline & \multicolumn{3}{c}{ VAS1 } & & \multicolumn{3}{c}{ VAS2 } \\
\cline { 2 - 4 } \cline { 6 - 7 } Variable & No & Yes & $\mathbf{P}$ & & No & Yes & $\mathbf{P}$ \\
\hline $\begin{array}{l}\text { Smoke } \\
\text { exposure }\end{array}$ & $23.0 \pm 23.1$ & $34.0 \pm 28.8$ & 0.003 & & $39.0 \pm 28.7$ & $51.0 \pm 28.4$ & 0.005 \\
Alcohol use & $21.0 \pm 20.8$ & $30.2 \pm 27.9$ & 0.010 & & $38.6 \pm 26.4$ & $45.7 \pm 30.7$ & 0.078 \\
Caffeine use & $31.6 \pm 28.0$ & $25.3 \pm 25.0$ & 0.161 & & $31.6 \pm 28.0$ & $25.3 \pm 24.9$ & 0.492 \\
Coping well & $29.6 \pm 26.5$ & $26.2 \pm 25.5$ & 0.629 & & $52.7 \pm 30.0$ & $42.1 \pm 29.0$ & 0.176 \\
$\begin{array}{c}\text { Objective } \\
\text { findings of } \\
\text { stress }\end{array}$ & $25.6 \pm 25.7$ & $33.3 \pm 23.8$ & 0.148 & & $41.4 \pm 29.3$ & $53.5 \pm 25.3$ & 0.046
\end{tabular}

Results presented as mean $\pm S D$ visual analogue scale (VAS) scores of standardized $0.1 \mathrm{~ms}$ suprathreshold electrical stimulations, consisting of one stimulation at $50 \mathrm{~mA}$ (VAS1), followed by one at $100 \mathrm{~mA}$ (VAS2)

of stress' was defined as one or both of dermatographia (25) and hyperhidrosis (26).

\section{RESULTS}

The characteristics of the 215 subjects included in the present study are shown in Table 1. Reliability analysis of measured VAS responses demonstrated excellent agreement, with correlation coefficients and the intra-class correlation all equal to $1.0(\mathrm{P}<0.001)$. The distribution of VAS1 was somewhat skewed to the right, but the VAS2 was not, and both measures were deemed to be sufficiently normally distributed to permit the use of robust parametric statistics. Despite current smokers being statistically significantly younger than those previously exposed to second-hand smoke $(\mathrm{P}=0.001)$, univariate ANOVA showed no significant interaction between age and smoke exposure $(\mathrm{P}=0.14$ and $\mathrm{P}=0.47$ for VAS1 and VAS2, respectively).

Table 2 contains the comparisons of VAS1 and VAS2 scores for the dichotomized smoke exposure variable, as well as other lifestyle factors. Significant differences were found in VAS scores for those currently exposed to smoke compared with those not exposed, for both VAS1 $(\mathrm{P}=0.003)$ and VAS2 $(\mathrm{P}=0.005)$. Examining the relationship between smoke exposure and pain more closely, the subset of nonsmokers who were exposed to second-hand smoke either currently or in the past was investigated. Subjects who were currently exposed to second-hand smoke had consistently higher mean VAS1 (26.4 versus 13.9) and VAS2 (36.9 versus 31.7) ratings than subjects who had been exposed to second-hand smoke in the past, although the differences fell short of significance largely due to the small sample sizes of eight (current exposure) and 37 (past exposure). Increased time since exposure was negatively associated with pain ratings for VAS1 $(\mathrm{r}=-0.155$,
$\mathrm{P}=0.067)$ and VAS2 $(\mathrm{r}=-0.149, \mathrm{P}=0.078)$, although both fell just short of statistical significance. Time since exposure was then categorized as less than one year, one to less than five years, five to less than 10 years, 10 to less than 15 years, and 15 years or greater. Using ANOVA, the results suggest that pain perception is significantly higher in subjects who were exposed within the past year. Subjects whose most recent exposure was more than one year before the present study reported levels of pain perception that were similar and, in some cases, even lower than subjects who had never been exposed $(\mathrm{P}=0.009$ and $\mathrm{P}=0.012$ for VAS1 and VAS2, when comparing less than one year to all other groups).

Subjects reporting regular alcohol use (128 [59.5\%] occasional or regular users) also reported more pain. Alcohol users had an average pain rating that was 9.2 points higher than nonusers for VAS1 $(\mathrm{P}=0.010)$ and 7.1 points higher for VAS2 $(\mathrm{P}=0.078)$. In fact, when the three levels were examined, mean reported pain increased in a stepwise fashion with each level of alcohol use. For VAS1, mean values were 21.0, 28.6 and 34.8 (none, occasional and regular, respectively, $\mathrm{P}=0.014$ ), while the values for VAS2 were 38.6, 43.9 and 51.2 (none, occasional and regular, respectively, $\mathrm{P}=0.082$ ).

Pearson's correlation analyses indicated that increased age was associated with reduced pain perception for both VAS1 $(\mathrm{r}=-0.125, \mathrm{P}=0.067)$ and VAS2 $(\mathrm{r}=-0.202, \mathrm{P}=0.003)$. Caffeine use (175 [81.4\%]) was not significantly associated with VAS1 or VAS2 scores. However, exhibiting objectively measureable signs of stress was associated with higher pain scores for VAS2, in 13 subjects with dermatographia, 12 with hyperhidrosis, and one with both of these clinical signs.

Table 3 contains the two regression models for VAS1 and VAS2. The models were similar in that current smoke exposure and current alcohol use were associated with higher pain ratings for both VAS1 and VAS2. In combination, current smoke exposure and alcohol use added 19.9 points to the VAS1 (10.9 for smoke, 9.0 for alcohol) and 18.0 points to the VAS2 (10.0 for smoke, 8.0 for alcohol). The models differed in that increased age was associated with lower pain ratings for VAS2 $(\mathrm{P}=0.009)$ but fell short of statistical significance for VAS1 $(\mathrm{P}=0.134)$, and presence of objective signs of stress was significantly associated with higher pain ratings for VAS2 $(\mathrm{P}=0.050)$ but not VAS1 $(\mathrm{P}=0.143)$. Both models were highly significant overall $(\mathrm{F}=8.0$ and $\mathrm{F}=5.8$ respectively, $\mathrm{P}<0.001$ for both) and accounted for 7\% (VAS1) and 10.1\% (VAS2) of the variation in outcome.

\section{DISCUSSION}

The results from this cohort of women with primarily intermittent localized extremity symptoms suggest an association between smoke exposure and higher initial pain sensitivity 
TABLE 3

Linear regression models for pain perception

\begin{tabular}{lccccc}
\hline & \multicolumn{2}{c}{\begin{tabular}{c} 
Model for VAS1 \\
\cline { 2 - 3 } Variable
\end{tabular}} & & \multicolumn{2}{c}{ Model for VAS2 } \\
\cline { 2 - 3 } \cline { 5 - 6 } & $\begin{array}{c}\text { Parameter } \\
\text { estimate }\end{array}$ & $\mathbf{P}$ & & $\begin{array}{c}\text { Parameter } \\
\text { estimate }\end{array}$ & $\mathbf{P}$ \\
\hline Intercept & 17.6 & $<0.001$ & & 50.9 & $<0.001$ \\
Current smoke exposure & 10.9 & 0.003 & & 10.0 & 0.017 \\
Current alcohol use & 9.0 & 0.010 & & 8.0 & 0.043 \\
Objective findings of stress & $\mathrm{n} / \mathrm{a}$ & $\mathrm{n} / \mathrm{a}$ & & 11.4 & 0.050 \\
Age/10 & $\mathrm{n} / \mathrm{a}$ & $\mathrm{n} / \mathrm{a}$ & & -3.5 & 0.009
\end{tabular}

Notes: $0=$ No, $1=$ Yes for the three categorical independent variables. Age was divided by 10 to make the parameter estimate more meaningful in that it now represents every 10 years of increased age. $n / a$ indicates that the variable did not attain statistical significance in the model (parameter estimate -1.7, $P=0.134$ for age; and 7.6, $P=0.143$ for findings of stress). VAS1 Visual analogue score of a standardized $0.1 \mathrm{~ms}$ suprathreshold electrical stimulation, consisting of one stimulation at $50 \mathrm{~mA}$; VAS2 Visual analogue scale score of a $0.1 \mathrm{~ms}$ suprathreshold electrical stimulation, consisting of one stimulation at $100 \mathrm{~mA}$

reported with electrical stimulation, with those reporting exposure scoring approximately 10 points higher on the VAS than those reporting no exposure. When considering the results of nonsmokers exposed to smoke, past and present, in the present study population, this association may warrant future study of nonsmokers who are and are not exposed to second-hand smoke, examining pain thresholds to various pain modalities. There may be a heightened anxiety response associated with electrical stimulation, and perhaps the difference in pain perception reported in the case of those exposed to smoke is a combination of heightened anticipatory anxiety and physiological pain response. Nevertheless, the differences remain significant between those with current exposure to cigarette smoke compared with those without current exposure.

Alcohol, caffeine, age and objective signs of stress showed trends in their associations with reported pain perception in our study, in keeping with relationships previously reported in the literature. Subjects with current alcohol use scored an average of 8.0 (VAS2) to 9.0 (VAS1) points higher than abstainers. Some alcohol users may consume alcohol for its analgesic effects and their higher pain scores may reflect their underlying higher pain condition. Though current smokers and ex-smokers were more likely to consume caffeine regularly, pain reports among regular caffeine consumers were generally lower than among those who denied regular caffeine intake, lending strength to the results of smoke exposure. This finding is in agreement with a previous report in which cigarette smoking and coffee drinking were found to coexist in individuals (30), which also suggested that caffeine increases pain thresholds. We found that the presence of clinical signs associated with stress, namely, dermatographia and situational hyperhidrosis, both readily recognizable by clinicians, are associated with higher pain perception. Older individuals reported less pain with the higher level of electrical stimulation, in keeping with reports in the literature. These relationships should be examined in sex-comparative studies with equal sex representation.

Physiological differences in pain tolerance and thresholds have been reported for men and women, in response to pain stimuli, including electrical stimulation (31). In general, women seem to report more pain, in both experimental and nonexperimental conditions $(12,32)$. One group reported that anxiety may have differing effects in men and women, indicating that men with low anxiety had greater pain tolerance than women with both low and high anxiety (33). With respect to trends in nicotine exposure, recent literature indicates that there is a general increase in smoking and tobacco use worldwide in girls and women (34-36). This increase in smoking rates in women is seen despite a general decline in smoking prevalence $(37,38)$.

The literature suggests that smoking is related to higher pain severity in populations with chronic pain $(1,2)$, though it could be that some people experiencing more pain may resort to smoking. Three studies (39-41) attempted to find a possible causal relationship between smoking and increased pain perception. One group looked at onset of ischemic pain in smokers, deprived smokers and nonsmokers (39). They found that smokers' indexes of pain were higher, and periods of pain tolerance were shorter, compared with nonsmokers and smokers deprived of cigarettes for more than $1 \mathrm{~h}$, indicating that smoking could possibly have a short-term, immediate effect on pain perception. However, the numbers were small, with 15 to 30 subjects in each category. Another group followed a cohort of high school students (40) and found that smoking was associated with the development of back pain (OR 2.20). Similarly, a Finnish group studied a large cohort of forest industry workers (41) and found that incidental sciatic pain occurred more frequently in older individuals, in those that smoked for at least 15 years and in those with mental stress. They found that ex-smokers did not have an increased risk of incidental pain. The effect of sex was not examined in these studies. The difficulty with longitudinal studies is the lack of a controlled environment. Nevertheless, a prospective longitudinal study using systematic validated measures of variables, including the independent variable of smoke exposure on pain perception, could help to shed light on causality.

Limitations of the present cross-sectional study include the inability to prove causation. In our sample, current smokers tended to be younger. Factors that were not examined in the present study, but may have had an impact on pain perception, included sleep and aerobic exercise. Sleep deprivation may affect the pain perception of some sensory modalities (42). Higher intensity aerobic exercise has been reported to affect pain experiences in women (43), though exercise did not seem to have an immediate effect on pain thresholds to electrical stimulation in one study (44). Another limitation is that an objective assessment of signs of stress does not provide information about type or impact of existing stressors. When asked about the stress in their lives (financial, work, health, family or other), $49.3 \%$ of the women reported no stressors, while $38.6 \%, 9.3 \%$ and $2.8 \%$ reported one, two or three stressors, respectively, with family stress being the most commonly reported $(27.4 \%)$. It may be worthwhile to use other validated and more detailed measures of stress in a future study. Another limitation is the small number of data points per subject (one at each of the two stimulus levels), which was a strategy used to avoid attenuation of perception of stimuli that could occur with repeated stimulation. Lastly, the subjects in the present study were referred for testing in an electromyography clinic due to localized discomfort or paresthesia in one or more extremities. We did not measure baseline pain levels because subjects typically did not have more than intermittent minor discomfort, and we excluded anyone who reported widespread or severe chronic pain. 


\section{CONCLUSION}

Our study provides further evidence of a positive association between smoke exposure and increased pain response to electrical stimulation in women that would warrant further longitudinal study with systematic measures and design to establish a causal mechanism between cigarette smoke exposure and pain perception. Such a study should ideally take into account and measure other associated factors that have been reported to be associated with pain perception, including stress, exercise, sleep, and alcohol and caffeine use in its design. Given that exposure to cigarette smoke may add 10 points to the 100 -point VAS, compared with subjects not exposed to cigarette smoke, it seems reasonable to counsel female patients who are experiencing pain to consider avoiding smoke exposure.

ACKNOWLEDGEMENTS: The authors thank the clinic nurses at Providence Care, St. Mary's of the Lake Site for assistance in the recruitment process.

\section{REFERENCES:}

1. Leboeuf-Yde, Charlotte DC. Smoking and low back pain:

A systematic literature review of 41 journal articles reporting

47 epidemiologic studies. Spine 1999;24:1463-76.

2. Goldberg MS, Scott SC, Mayo NE. A review of the association between cigarette smoking and the development of nonspecific back pain and related outcomes. Spine 2000;25:995-1014

3. Nyiendo J, Haas M, Goldberg B, Sexton G. Pain, disability, and satisfaction outcomes and predictors of outcomes: A practice-based study of chronic low back pain patients attending primary care and chiropractic physicians. J Manipulative Physiol Ther 2001;24:433-9.

4. Nathan PA, Meadows KD, Istvan JA. Predictors of carpal tunnel syndrome. J Hand Surg 2002;27:644-51.

5. Hsu C, Harden RN, Houle T. Nicotine and caffeine intake in complex regional pain syndrome. J Back Musculoskeletal Rehabil 2002;16:33-8

6. Holmen TL, Barrett-Connor E, Holmen J, Bjermer L. Health problems in teenage daily smokers versus nonsmokers, Norway. 1995-1997: The Nord-Trondelag Health Study. Am J Epidemiol 2000;151:148-55.

7. Lane JD, Lefebvre JC, Rose JE, Keefe FJ. Effects of cigarette smoking on perception of thermal pain. Exp Clin Psychopharmacol 1995;3:140-7.

8. Fertig JB, Pomerleau OF, Sanders B. Nicotine-produced antinociception in minimally deprived smokers and ex-smokers. Addict Behav 1986;11:239-48.

9. Shiffman S, Jarvik ME. Cigarette smoking, physiological arousal, and emotional response: Nesbitt's paradox re-examined. Addict Behav 1984;9:95-8

10. Benbow SJ, Williams G, MacFarlane IA. Smoking habits and painful diabetic neuropathy. J Diabetes Complications 1997;11:334-7.

11. Jamner LD, Girdler SS, Shapiro D, Jarvik ME. Pain inhibition, nicotine, and gender. Exp Clin Psychopharmacol 1998;6:96-106.

12. Sherman JJ, LeResche L. Does experimental pain response vary across the menstrual cycle? A methodological review. Am J Physiol Regul Integr Comp Physiol 2006;295:R245-56.

13. Melzack R. Evolution of the neuromatrix theory of pain. The Prithvi Raj Lecture: Presented at the third World Congress of World Institute of Pain, Barcelona 2004. Pain Pract 2005;5:85-94.

14. Miklos IH, Kovacs KJ. Functional heterogeneity of the response of histaminergic neuron subpopulations to various stress challenges. Eur J Neurosci 2003;18:3069-79.

15. Sterling P, Eyer J. Allostasis: A new paradigm to explain arousal pathology. In: Fisher S, Reason J, eds. Handbook of Life Stress, Cognition, and Health. New York: John Wiley \& Sons, 1988:629-49.

16. Vengeliene V, Siegmund S, Singer MV, Sinclair JD, Li TK, Spanagel R. A comparative study on alcohol-preferring rat lines: Effects of deprivation and stress phases on voluntary alcohol intake. Alcohol Clin Exp Res 2003;27:1048-54.

17. Chester JA, de Paula Barrenha G, DeMaria A, Finegan A. Different effects of stress on alcohol drinking behaviour in male and female mice selectively bred for high alcohol preference. Alcohol Alcohol 2006;41:44-53.

18. Kimpel MW, Brown MM, Froehlich JC. Pain thresholds in alcohol preferring and non-preferring rats: Diurnal and repeated trial line differences. Alcohol Clin Exp Res 2003;27:1921-8.

19. Coghill RC, Eisenach J. Individual differences in pain sensitivity: Implications for treatment decisions. Anesthesiology 2003;98:1312-4.

20. Motl RW, O'Connor PJ, Tubandt L, Puetz T, Ely MR. Effect of caffeine on leg muscle pain during cycling exercise among females. Med Sci Sports Exerc 2006;38:598-604.

21. The development of pain perception and principles of pain control. In: Lewis M, ed. Child \& Adolescent Psychiatry: A Comprehensive Textbook, 3rd edn. Lippincott Williams \& Wilkins, 2002.

22. Oral complications. In: DeVita VT, Hellman S, Rosenberg SA, eds. Cancer: Principles \& Practice of Oncology, 7th edn. Lippincott Williams \& Wilkins, 2005.

23. Gibson SJ, Farrell M. A review of age differences in the neurophysiology of nociception and the perceptual experience of pain. Clin J Pain 2004;20:227-39.

24. Folstein MF, Folstein SE, McHugh PR. "Mini-mental state". A practical method for grading the cognitive state of patients for the clinician. J Psychiatr Res 1975;12:189-98.

25. Taskapan O, Harmanyeri Y. Evaluation of patients with symptomatic dermatographism. J Eur Acad Dermatol Venereol 2006;20:58-62.

26. Dyshidrosis. In: FJ Domino, ed. The 5-Minute Clinical Consult, 2007 edn. Lippincott Williams \& Wilkins, 2007.

27. Bushbacher RM. Manual of Nerve Conduction Studies. New York: Demos Medical Publishing Inc, 2000.

28. Nemeth K, Graham I, Harrison M. The measurement of leg ulcer pain: Identification and appraisal of pain assessment tools. Adv Skin Wound Care 2003;16:260-7.

29. Patrician P. Single-item graphic representational scales. Nurs Res 2004;53:347-52.

30. Nastase A, Ioan S, Braga RI, Zagrean L, Moldovan M. Coffee drinking enhances the analgesic effect of cigarette smoking. Neuroreport 2007;18:921-4.

31. Chung JWY, Wong TKS, Clark CW. Gender differences in pain responses to calibrated noxious heat stimuli: A sensory decision theory analysis. The Pain Clinic 2004;16:131-7.

32. Bergh I, Sjostrom B. Quantification of the pain terms hurt, ache and pain among nursing students. Scand J Caring Sci 2007;21:163-8.

33. Davidson MD, Davidson PR, Tripp DA, Borschch Y. Cigarette smoking and chronic pain: Relationship to pain severity and affective distress. Poster presentation 2005, Queen's University.

34. Gritz ER. Women's smoking in the 21st century: Trends, determinants and cessation: M16-04. J Thoracic Oncol 2007;2(Suppl 4):S195-7.

35. Gilmore A, Pomerleau J, McKee M, et al. Prevalence of smoking in 8 countries of the former Soviet Union: Results from the living conditions, lifestyles and health study. Am J Public Health 2004;94:2177-87.

36. Carpenter C, Wayne G, Connolly G. Designing cigarettes for women: New findings from the tobacco industry documents. Addiction 2005;100:837-51.

37. Escobedo LG, Peddicord JP. Smoking prevalence in US birth cohorts: The influence of gender and education. Am J Public Health 1996;86:231-6.

38. Stewart DE. Women's health comes of age. CMAJ 1997;157:1711-2.

39. Mildrom-Friedman J, Penman R, Meares R. A preliminary study on pain perception and tobacco smoking. Clin Exp Pharmacol Physiol 1983;10:161-9.

40. Feldman DE, Shrier I, Rossignol M, Abenhaim L. Risk factors for the development of low back pain in adolescence. Am J Epidemiol 2001;154:30-6.

41. Miranda H, Viikari-Juntura E, Martikainen R, Takala EP, Riihimäki H. Individual factors, occupational loading, and physical exercise as predictors of sciatic pain. Spine 2002;27:1102-8

42. Kundermann B, Spernal J, Huber MT, Krieg J-C, Lautenbacher S. Sleep deprivation affects thermal pain thresholds but not somatosensory thresholds in healthy volunteers. Psychosom Med 2004;66:932-7.

43. Emeda M, Koltyn KF. Influence of aerobic exercise intensity on alterations in pain perception in women. Med Sci Sports Exerc 2005;37(Suppl):S332. (Abst)

44. Droste C, Meyer-Blankenburg H, Greenlee MW, Roskamm H. Effect of physical exercise on pain thresholds and plasma beta-endorphins. Eur Heart J 1988;9(Suppl N):25-33. 


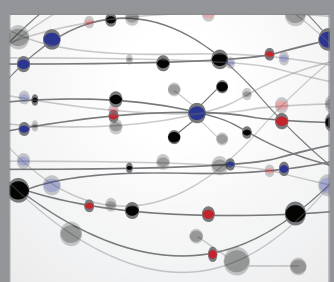

The Scientific World Journal
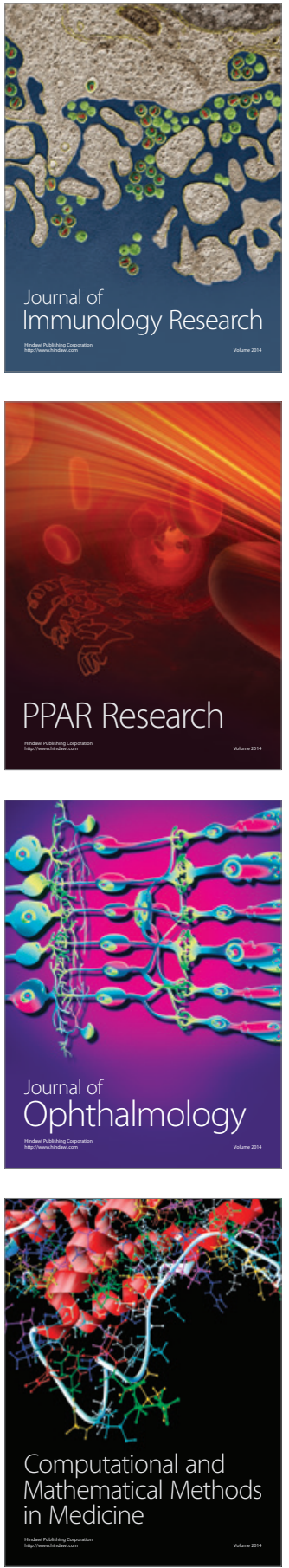

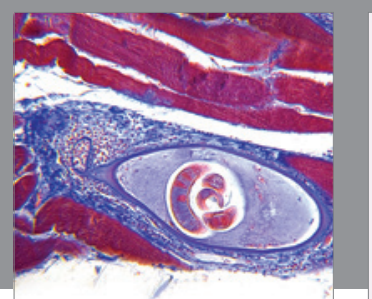

Gastroenterology Research and Practice

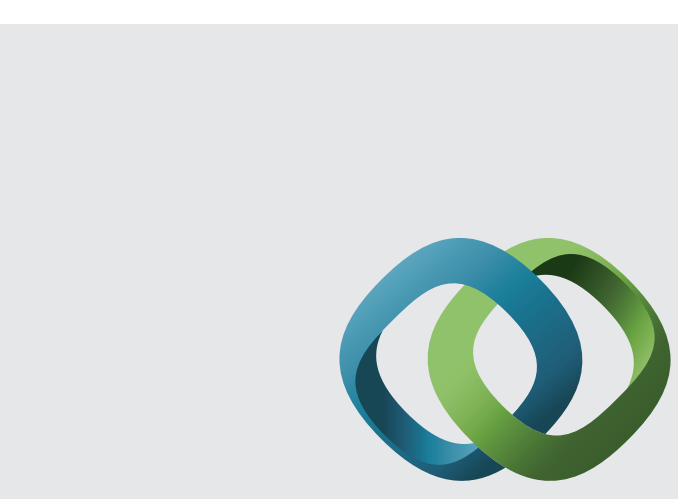

\section{Hindawi}

Submit your manuscripts at

http://www.hindawi.com
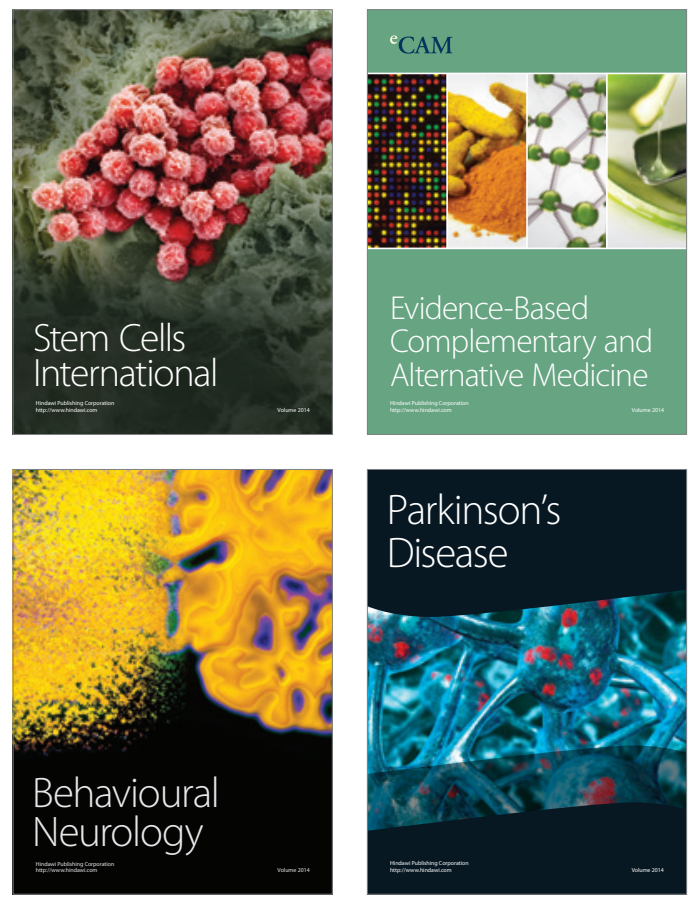
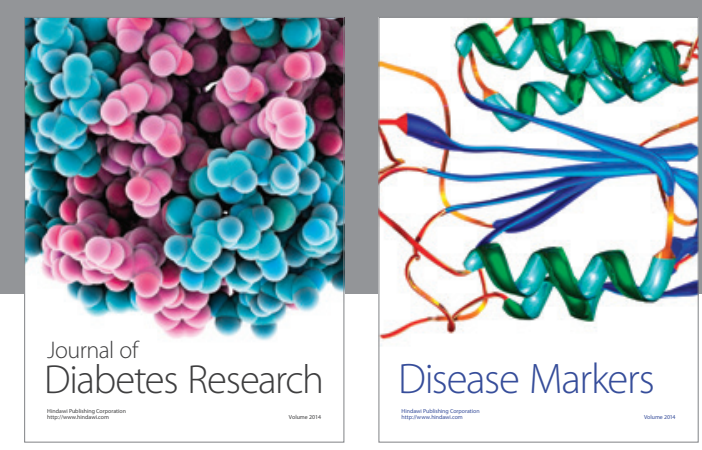

Disease Markers
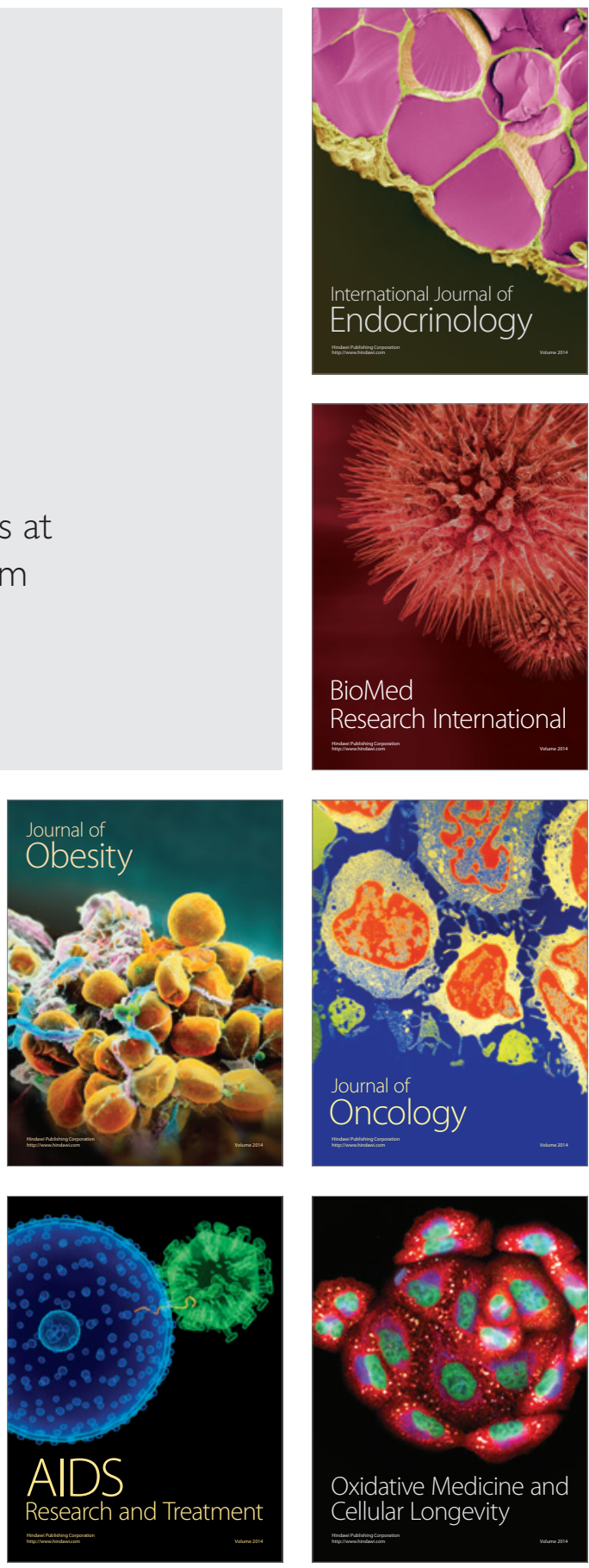